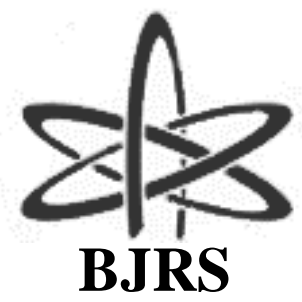
BRAZILIAN JOURNAL OF RADIATION SCIENCES 07-02B (2019) 01-18

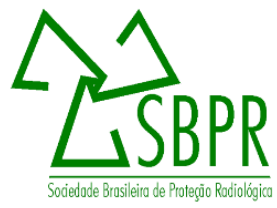

\title{
Energy and Exergy Analyses of Angra 2 Nuclear Power Plant
}

\author{
J. G. O. Marques, A. L. Costa, C. Pereira, Â. Fortini \\ Universidade Federal de Minas Gerais \\ Departamento de Engenharia Nuclear - Escola de Engenharia \\ Av. Antônio Carlos N ${ }^{o}$ 6627, Campus Pampulha, CEP 31270-901, Belo Horizonte, MG, Brasil \\ antonella@nuclear.ufmg.br
}

\begin{abstract}
Nuclear Power Plants (NPPs) based on Pressurized Water Reactors (PWRs) technology are considered an alternative to fossil fuels plants due to their reliability with low operational cost and low $\mathrm{CO}_{2}$ emissions. An example of PWR plant is Angra 2 built in Brazil. This NPP has a nominal electric power output of 1,300 MW and made it possible for the country save its water resources during electricity generation from hydraulic plants, and improved Brazilian knowledge and technology in nuclear research area. Despite all these benefits, PWR plants generally have a relatively low thermal efficiency combined with a large amount of irreversibility generation or exergy destruction in their components, reducing their capacity to produce work. Because of that, it is important to assess such systems to understand how each component impacts on system efficiency. Based on that, the aim of this work is to evaluate Angra 2 by performing energy and exergy analyses to quantify the thermodynamic performance of this PWR plant and its components. The methodology consists in the development of a mathematical model in EES (Engineering Equation Solver) software based on thermodynamic states in addition to energy and exergy balance equations. According to the results, Angra 2 has energy efficiency of $36.18 \%$ and exergy efficiency of $49.24 \%$. Reactor core is the most inefficient device in the NPP; it has exergy efficiency of $67.16 \%$ and is responsible for $63.88 \%$ of all exergy destroyed in Angra 2.
\end{abstract}

Keywords: Angra 2, Nuclear Power Plant, Pressurized Water Reactor, Thermal Efficiency.

ISSN: 2319-0612

Accepted: 2019-05-20 


\section{INTRODUCTION}

Global warming is one of the main environmental concerns of society. This effect is directly related to $\mathrm{CO}_{2}$ emissions, especially by burning fossil fuels in power plants to produce electricity. An alternative to fossil fuels and their environmental issues are renewable energy sources, such as, hydro, biomass and solar. These resources have potential to supply energy needs of society in sustainable manner, as pointed out by Ozcan and Dincer [1].

However, according to Komiyama and Fujii [2], the power output of renewable resources is directly affected by the seasonality and variability of climate conditions such as solar insolation. Additionally, Khalid et al. [3] believe that the intermittency of renewable energies creates barriers and challenges for their use in industrial activities. In this sense, Huhtala and Remes [4] emphasize nuclear technologies can supply energy in a reliable way with low operational cost and low $\mathrm{CO}_{2}$ emissions. One possible nuclear technology for electricity production is PWR that represents the majority of the world's NPPs [5]. Generally, a PWR power plant converts nuclear energy into thermal one by using the heat released from nuclear fission. Thermal energy is then used to boil water and produce steam that will drive a turbine to produce electricity. According to Ozcan e Dincer [1], NPPs have thermal efficiency around $35 \%$ and they represent $16 \%$ of the worldwide electricity demand.

Besides thermal or energy efficiency, exergy is an alternative way to evaluate any kind of thermal systems, including nuclear ones. An exergy analysis allows evaluating the performance of a system and its components by quantifying irreversibility generation in each device of the power plant [6, 7]. In literature, there are many papers addressing energy and exergy analyses to evaluate a wide variety of nuclear systems or NPPs.

Durmayas and Yavuz [8] performed an exergy analysis in a pressurized water reactor with a thermal capacity of 4,250 MW in order to assess the irreversibility related to the NPP and its components. The authors focused their attention in how much of the available work is loss due to irreversibility. The results of this study indicate that the reactor is the least efficient device in the nuclear power plant. In another way, Zare et al. [9] proposed a combined cycle of a gas turbine-modular helium reactor (GT-MHR) with an ammonia-water mixture (AWM) cycle. This concept allows utilizing waste heat from GT-MHR to produce both cooling effect and additional work. The authors carried out a thermodynamic analysis and conclude that the exergy efficiency of the hybrid cycle can be around from $4 \%$ to $10 \%$ higher than that one of the common GT-MHR cycle. Similarly, Yari and Mahmoudi [10] compared two nuclear systems, a classic GT-MHR cycle and an Organic Rankine Cycle with a GT-MHR (GT-MHR/ORC). The organic Rankine cycle reuses waste energy from 
GT-MHR to produce additional work by superheating low boiling temperature fluids, such as, refrigerant ones like R123. According to the results, the GT-MHR/ORC have both energy and exergy efficiencies higher than the classical GT-MHR cycle.

Additionally, in the works [1] and [11] were proposed different hybrid systems for both electricity and hydrogen production by using the energy provided by a CANDU super critical water reactor (SCWR). According to the results, the system proposed by [1] has energy and exergy efficiencies of $18.6 \%$ and $31.35 \%$, respectively, while that one analyzed by [11] has energy and exergy efficiencies of $31.6 \%$ and $56.2 \%$, respectively.

Besides that, Khalid et al. [3] compared two nuclear technologies, CANDU 6 and a Sodium-cooled Fast Reactor (SFR), for desalination processes. The authors applied the concept of exergy to assess the performance of a desalination process due to each technology. According to the results, a desalination process based on CANDU 6 has exergy efficiency of $49.2 \%$, while the same process based on SFR has exergetic efficiency of $63.3 \%$. On the other hand, the study developed by Terzi et al. [12] performed an exergy analysis in a water-cooled water-moderated power reactor (VVER) with a thermal capacity of 3,900 MW and a nominal electric power of 1,000 MW. According to the results, the overall thermodynamic efficiency of this nuclear technology is around $30 \%$.

Therefore, based on the papers available in the literature, there is a wide variety of information about energy and exergy models covering many types of nuclear plants or systems in many countries worldwide, but none of them addressing a Brazilian NPP, not even Angra 1 or Angra 2. So, the aim of this work is to evaluate Angra 2, a nuclear power plant built in Brazil, by performing both energy and exergy analyses. In this way, it will be possible to determine Angra 2 thermodynamic performance and which of its components are the most inefficient; moreover it will be verified if the Brazilian NPP has thermodynamic efficiency close to other nuclear power plants.

\section{METHODOLOGY}

In this section are described the main steps need to develop the paper and consequently achieve its aim. Basically, the first step consists in defining the system or NPP studied, including its thermodynamic cycle and components like reactor, turbines, heaters and pumps. In the second step are determined the values of thermodynamic properties (pressure, temperature, quality, enthalpy and entropy) related to each point of the power plant, based on source data provided by Final Safety Analysis Report (FSAR) [13]. The basic law of mass balance is used during the third step to determine mass flow rate in every device of the NPP. Finally, in fourth and fifth steps, using the values of 
thermodynamic properties and mass flow rate from the previous steps are respectively applied energy and exergy balances to determine system energy (or thermal) and exergy efficiencies.

The steps 2 to 5 are implemented using the software Engineering Equation Solver (EES), available at Universidade Federal de Minas Gerais (UFMG). The equations about mass, energy and exergy balances applied during steps 3 to 5 can be easily found in basic thermodynamics books like those ones found in the references [14, 15 and 16].

\subsection{System description}

Angra 2 is the second NPP built in Brazil and has a nominal electric power output of 1300 MW. Such energy is able to supply the need of electricity of a city with 2 million inhabitants [17]. Angra 2 is a PWR technology from SIEMENS Corporation. In a simply way, a PWR plant consists by three main circuits: primary, secondary and tertiary. In primary circuit, liquid water coolant at high pressure removes heat from nuclear fission at reactor core. After that, in secondary circuit, liquid water coolant at high pressure and now at high temperature boils water to produce steam in steam generator (SG). This steam will drive both a high pressure turbine (HPT) and a low pressure turbine (LPT) to produce electricity. The secondary circuit is based on a Rankine cycle like the most steam power plants. Finally, in the third circuit, seawater cools steam, in condenser, after it leaves low pressure turbine. This cooling process is necessary to guarantee all the thermodynamic processes in the plant, including reactor cooling, steam generation and also electricity production.

Besides all processes and equipments described above, Angra 2 has many other devices necessary for its satisfactory operation. They are: low pressure heaters (LPHs), high pressure heaters (HPHs), pumps, feedwater tank (FWT), water or moisture separator (MS) and reheater (RH). Both LPHs and HPHs preheat water, by recovering heat to increase its temperature, before it reaches steam generator in order to increase system thermal efficiency. Similarly, reheater superheats steam before it drives low pressure turbine, increasing system overall performance. All these devices and their position in the NPP, alongside with the thermodynamic cycle for system, can be seen in Figure 1.

Figure 1 represents the thermodynamic cycle of the system from a simplified version of the thermal diagram for Angra 2 presented in FSAR [13]. The points numbered from 1 to 43 in this figure represent thermodynamic states and are used in next sections to develop both energy and exergy models. 
Figure 1: Angra 2 NPP Thermodynamic Cycle

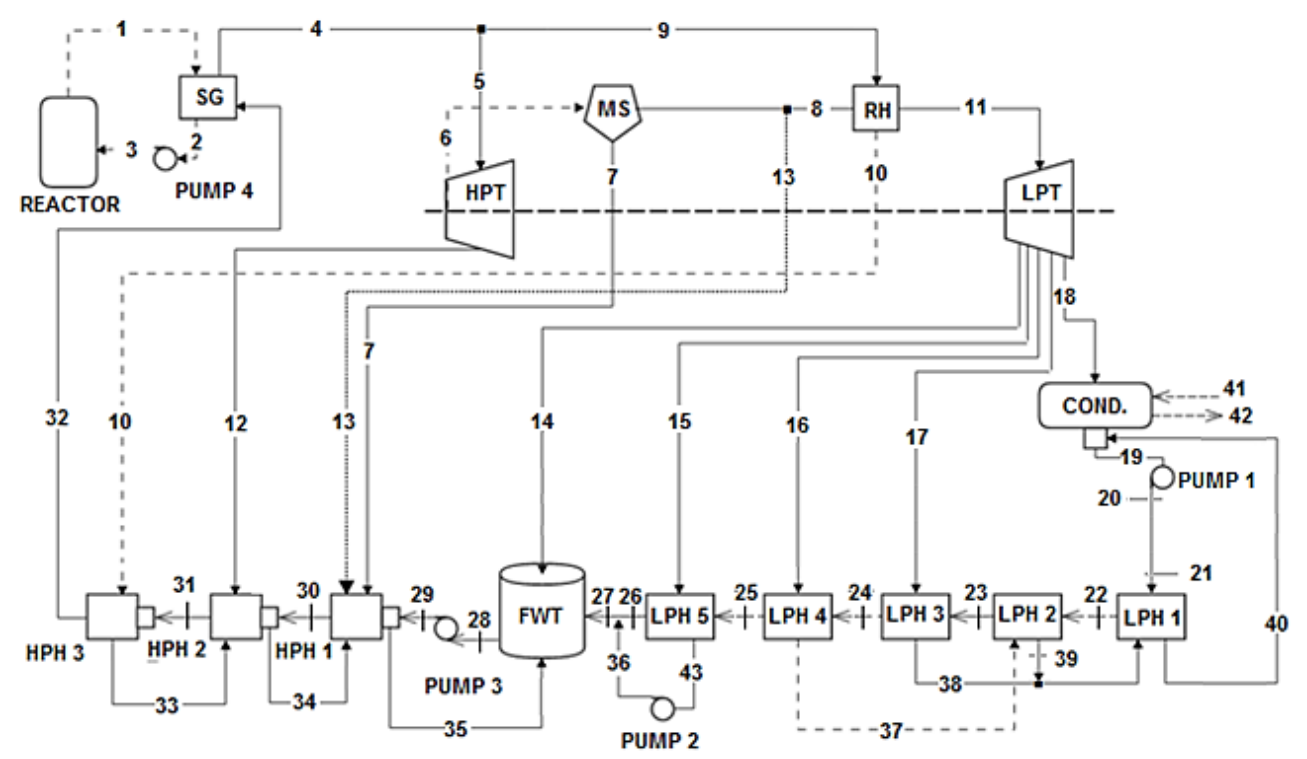

Source: adapted from FSAR [13].

\subsection{Defining thermodynamic states and properties}

Using reference data from FSAR [13] was determined the thermodynamic state in every point of the NPP defined in Figure 1. The values of pressure and temperature or quality provided by FSAR [13], to the points 1 to 43, were implemented in EES software to obtain the values of enthalpy and entropy related to every point, using water as working fluid. Additionally, point 0 refers to water at dead state condition. So, the obtained values of thermodynamic properties are shown in Table 1 and are used latter during energy and exergy calculations. The values -100 and 100 at quality column in Table 1, are respectively designate as subcooled liquid and superheated steam, while the values between 0 and 1 represent saturated condition or two phase liquid-vapor.

Additionally, Table 1 also presents the flow values of mass, energy and exergy for each point of the NPP. Such parameters are calculated in next sections, but they are already shown here in order to allow visualization in a single table of all the thermodynamic variables and properties involved in paper development.

\subsection{Mass balance equations}


The basic law of mass balance for each component of the nuclear power plant, considering steady state conditions, is:

$$
\sum \dot{m}_{\text {in }}=\sum \dot{m}_{\text {out }}
$$

Equations from (2) to (24) are obtained when implementing Eq. (1) in EES software for every single component of the NPP. In addition to these equations and using Table 2 with the input values of mass flow rate from FSAR [13] is possible to determine the mass flow rate in every point of the system, as previously shown in Table 1. Additionally, mass flow rate in points 1, 2 and 3 are obtained later by energy analysis considering reactor and steam generator.

Table 1: Thermodynamic properties based on FSAR [13] source data.

\begin{tabular}{|c|c|c|c|c|c|c|c|c|}
\hline $\begin{array}{l}\text { State } \\
\text { Point, } \\
\text { i }\end{array}$ & $\begin{array}{c}\text { Pressure } \\
\mathbf{P},[\text { bar }]\end{array}$ & $\begin{array}{c}\text { Temperature } \\
\mathbf{T},\left[{ }^{\circ} \mathbf{C}\right]\end{array}$ & $\begin{array}{c}\text { Quality } \\
x,[-]\end{array}$ & $\begin{array}{l}\text { Enthalpy } \\
\text { h,[kJ/kg] }\end{array}$ & $\begin{array}{c}\text { Entropy } \\
\mathrm{s},\left[\mathrm{kJ} / \mathrm{kg}^{*} \mathrm{~K}\right]\end{array}$ & $\begin{array}{c}\text { Mass flow } \\
\dot{m},[\mathrm{~kg} / \mathrm{s}]\end{array}$ & $\begin{array}{c}\text { Energy } \\
\text { flow } \\
E,[\mathrm{MW}]\end{array}$ & $\begin{array}{c}\text { Exergy } \\
\text { flow } \\
E_{x} x,[\mathrm{MW}]\end{array}$ \\
\hline $\mathbf{0}$ & 1 & 25 & -100 & 104.8 & 0.3669 & 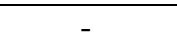 & - & - \\
\hline 1 & 157 & 324.9 & -100 & $1,482.33$ & 3.472 & $19,643.87$ & 29,119 & 8,874 \\
\hline 2 & 157 & 291.1 & -100 & $1,289.18$ & 3.14 & $19,643.87$ & 25,324 & 7,025 \\
\hline 3 & 163.5 & 291.4 & -100 & $1,290.38$ & 3.14 & $19,643.87$ & 25,348 & 7,045 \\
\hline 4 & 66.41 & 282.3 & 0.998 & $2,773.33$ & 5.834 & $2,069.35$ & 5,739 & 2,149 \\
\hline 5 & 66.22 & 282.1 & 0.9961 & $2,770.66$ & 5.83 & $1,943.04$ & 5,384 & 2,015 \\
\hline 6 & 11.65 & 186.7 & 0.8676 & $2,519.75$ & 5.96 & $1,781.56$ & 4,489 & 1,332 \\
\hline 7 & 11.46 & 185.9 & -100 & 789.37 & 2.197 & 230.60 & 182 & 32.06 \\
\hline 8 & 11.46 & 185.9 & 0.9971 & $2,776.94$ & 6.526 & $1,456.71$ & 4,045 & 1,217 \\
\hline 9 & 59.19 & 274.7 & 0.9927 & $2,773.30$ & 5.874 & 126.31 & $3,50.3$ & 129.7 \\
\hline 10 & 57.53 & 272.8 & -100 & $1,198.85$ & 3.001 & 126.31 & 151.4 & 39 \\
\hline 11 & 11.08 & 237.7 & 100 & $2,909.98$ & 6.816 & $1,456.71$ & 4239 & 1,285 \\
\hline 12 & 22.85 & 219.3 & 0.8933 & $2,602.49$ & 5.887 & 161.49 & 420.3 & 137.6 \\
\hline 13 & 11.46 & 185.9 & 0.9971 & $2,776.94$ & 6.526 & 94.24 & 261.7 & 78.76 \\
\hline 14 & 4.96 & 164.3 & 100 & $2,777.23$ & 6.891 & 66.96 & 186 & 48.69 \\
\hline 15 & 2.378 & 125.8 & 0.9727 & $2,654.85$ & 6.92 & 83.36 & 221.3 & 49.7 \\
\hline 16 & 0.891 & 96.44 & 0.8281 & $2,280.52$ & 6.344 & 116.34 & 265.3 & 45.8 \\
\hline 17 & 0.158 & 55.06 & 0.3258 & $1,002.53$ & 3.121 & 69.92 & 70.09 & 5.354 \\
\hline 18 & 0.0763 & 40.62 & 0.897 & $2,326.83$ & 7.454 & $1,120.13$ & 2606 & 122 \\
\hline 19 & 0.0763 & 36.6 & -100 & 153.28 & 0.5266 & $1,306.39$ & 200.2 & 1.081 \\
\hline 20 & 14.54 & 36.7 & -100 & 154.99 & 0.5274 & $1,306.39$ & 202.5 & 2.995 \\
\hline 21 & 9.39 & 36.7 & -100 & 154.53 & 0.5276 & $1,306.39$ & 201.9 & 2.321 \\
\hline 22 & 8.89 & 38 & -100 & 159.92 & 0.5452 & $1,306.39$ & 208.9 & 2.538 \\
\hline 23 & 8.4 & 42.5 & -100 & 178.69 & 0.6052 & $1,306.39$ & 233.4 & 3.669 \\
\hline 24 & 7.9 & 52.5 & -100 & 220.45 & 0.7356 & $1,306.39$ & 288 & 7.431 \\
\hline 25 & 7.41 & 92.2 & -100 & 386.70 & 1.217 & $1,306.39$ & 505.2 & 36.95 \\
\hline 26 & 6.92 & 124.3 & -100 & 522.41 & 1.574 & $1,306.39$ & 682.5 & 75.52 \\
\hline 27 & 6.92 & 124.4 & -100 & 522.83 & 1.575 & $1,389.75$ & 726.6 & 80.48 \\
\hline 28 & 5 & 151.6 & -100 & 639.23 & 1.858 & $2,069.35$ & 1,323 & 185.7 \\
\hline 29 & 82.65 & 152.9 & -100 & 649.60 & 1.863 & $2,069.35$ & 1,344 & 204.4 \\
\hline 30 & 81.67 & 182 & -100 & 775.67 & 2.149 & $2,069.35$ & 1,605 & 288.5 \\
\hline 31 & 80.69 & 215.9 & -100 & 926.51 & 2.469 & $2,069.35$ & 1,917 & 403.4 \\
\hline 32 & 69.66 & 218.9 & -100 & 939.81 & 2.499 & $2,069.35$ & 1,945 & 412.5 \\
\hline 33 & 57.53 & 226.7 & -100 & 975.29 & 2.573 & 126.31 & 123.2 & 26.86 \\
\hline 34 & 22.85 & 185 & -100 & 785.93 & 2.186 & 287.80 & 226.2 & 39.91 \\
\hline
\end{tabular}




\begin{tabular}{lcccccccc}
\hline $\mathbf{3 5}$ & 22.85 & 158.5 & -100 & 670.13 & 1.926 & 612.64 & 410.5 & 61.55 \\
$\mathbf{3 6}$ & 6.92 & 125.8 & -100 & 528.79 & 1.59 & 83.36 & 44.08 & 4.953 \\
$\mathbf{3 7}$ & 0.891 & 96.4 & -100 & 403.88 & 1.266 & 116.34 & 46.99 & 3.603 \\
$\mathbf{3 8}$ & 0.158 & 55 & -100 & 230.24 & 0.7679 & 69.92 & 16.1 & 0.4079 \\
$\mathbf{3 9}$ & 0.891 & 46.3 & -100 & 193.92 & 0.6555 & 116.34 & 22.56 & 0.3522 \\
$\mathbf{4 0}$ & 0.891 & 42.3 & -100 & 177.19 & 0.6029 & 186.26 & 33 & 0.3745 \\
$\mathbf{4 1}$ & 1 & 25 & -100 & 104.84 & 0.3669 & 291,011 & 305103 & 0 \\
$\mathbf{4 2}$ & 1 & 27 & -100 & 105.68 & 0.3697 & 291,011 & 307538 & 0.8162 \\
$\mathbf{4 3}$ & 2.378 & 125.7 & -100 & 528.14 & 1.589 & 83.36 & 44.03 & 4.909 \\
\hline
\end{tabular}

Table 2: Input values of mass flow rate based on FSAR [13] source data.

\begin{tabular}{cc}
\hline $\begin{array}{c}\text { State } \\
\text { Point, i }\end{array}$ & $\begin{array}{c}\text { Mass Flow } \\
\dot{\boldsymbol{m}},[\mathrm{kg} / \mathbf{s}]\end{array}$ \\
\hline $\mathbf{4}$ & $2,069.35$ \\
$\mathbf{5}$ & $1,943.040$ \\
$\mathbf{6}$ & $1,781.555$ \\
$\mathbf{7}$ & 230.604 \\
$\mathbf{1 3}$ & 94.237 \\
$\mathbf{1 4}$ & 66.964 \\
$\mathbf{1 5}$ & 83.363 \\
$\mathbf{1 6}$ & 116.34 \\
$\mathbf{1 7}$ & 69.917 \\
\hline
\end{tabular}

(i) Mass balance for reactor and steam generator;

$$
\begin{gathered}
\dot{m}_{1}=\dot{m}_{2}=\dot{m}_{3} \\
\dot{m}_{4}=\dot{m}_{32}
\end{gathered}
$$

(ii) Mass balance for low and high pressure heaters;

$$
\begin{gathered}
\dot{m}_{19}=\dot{m}_{20}=\dot{m}_{21}=\dot{m}_{22}=\dot{m}_{23}=\dot{m}_{24}=\dot{m}_{25}=\dot{m}_{26} \\
\dot{m}_{36}=\dot{m}_{15}=\dot{m}_{43} \\
\dot{m}_{37}=\dot{m}_{16} \\
\dot{m}_{38}=\dot{m}_{17} \\
\dot{m}_{39}=\dot{m}_{37} \\
\dot{m}_{40}=\dot{m}_{38}+\dot{m}_{39} \\
\dot{m}_{43}=\dot{m}_{15} \\
\dot{m}_{28}=\dot{m}_{29}=\dot{m}_{30}=\dot{m}_{31}=\dot{m}_{32}
\end{gathered}
$$




$$
\begin{gathered}
\dot{m}_{33}=\dot{m}_{10} \\
\dot{m}_{34}=\dot{m}_{12}+\dot{m}_{33} \\
\dot{m}_{35}=\dot{m}_{13}+\dot{m}_{34}+\dot{m}_{7}
\end{gathered}
$$

(iii) Mass balance for feedwater tank, moisture separator, reheater and condenser;

$$
\begin{gathered}
\dot{m}_{27}=\dot{m}_{26}+\dot{m}_{36} \\
\dot{m}_{28}=\dot{m}_{14}+\dot{m}_{27}+\dot{m}_{35} \\
\dot{m}_{8}=\dot{m}_{6}-\dot{m}_{7}-\dot{m}_{13} \\
\dot{m}_{8}=\dot{m}_{11} \\
\dot{m}_{9}=\dot{m}_{10} \\
\dot{m}_{19}=\dot{m}_{18}+\dot{m}_{40} \\
\dot{m}_{41}=\dot{m}_{42}
\end{gathered}
$$

(iv) Mass balance for low and high pressure turbines;

$$
\begin{gathered}
\dot{m}_{9}=\dot{m}_{4}-\dot{m}_{5} \\
\dot{m}_{12}=\dot{m}_{5}-\dot{m}_{6} \\
\dot{m}_{18}=\dot{m}_{11}-\dot{m}_{14}-\dot{m}_{15}-\dot{m}_{16}-\dot{m}_{17}
\end{gathered}
$$

\subsection{Energy model}

The first law of thermodynamics for a control volume accounts energy exchange in many devices, such as turbines, pumps, compressors and heaters. If kinetic and potential energies can be neglected during steady state conditions, the first law simply becomes in Eq. (25). Such statement is the foundation for the energy model proposed in this section, used to evaluate the system and its components.

$$
\dot{Q}-\dot{W}=\sum \dot{m}_{\text {out }} h_{\text {out }}-\sum \dot{m}_{\text {in }} h_{\text {in }}
$$


Besides that, the values of energy flow $\left(\dot{E}_{i}\right)$ to each thermodynamic state, previously shown in Table 1, are calculated by implementing Eq. (26) in ESS software with the values of enthalpy and mass flow.

$$
\dot{E}_{i}=\dot{m}_{i} h_{i}
$$

Then, by implementing in EES software Eq. (25) for every individual component of Angra 2 NPP are obtained the following energy variables:

(i) The total thermal power released by reactor and added to steam generator (SG);

$$
\begin{gathered}
\dot{P}_{\text {Reactor }}=\dot{m}_{1}\left(h_{1}-h_{3}\right) \\
\dot{Q}_{S G}=\dot{m}_{1}\left(h_{1}-h_{2}\right)=\dot{m}_{4}\left(h_{4}-h_{32}\right)
\end{gathered}
$$

(ii) Heat exchanged in low pressure heaters (LPHs) and high pressure heaters (HPHs);

$$
\begin{gathered}
\dot{Q}_{L P H, 1}=\dot{m}_{20}\left(h_{22}-h_{21}\right)=\dot{m}_{38} h_{38}+\dot{m}_{39} h_{39}-\dot{m}_{40} h_{40} \\
\dot{Q}_{L P H, 2}=\dot{m}_{20}\left(h_{23}-h_{22}\right)=\dot{m}_{37}\left(h_{37}-h_{39}\right) \\
\dot{Q}_{L P H, 3}=\dot{m}_{20}\left(h_{24}-h_{23}\right)=\dot{m}_{17}\left(h_{17}-h_{38}\right) \\
\dot{Q}_{L P H, 4}=\dot{m}_{20}\left(h_{25}-h_{24}\right)=\dot{m}_{16}\left(h_{16}-h_{37}\right) \\
\dot{Q}_{L P H, 5}=\dot{m}_{20}\left(h_{26}-h_{25}\right)=\dot{m}_{15}\left(h_{15}-h_{36}\right) \\
\dot{Q}_{H P H, 1}=\dot{m}_{30}\left(h_{30}-h_{29}\right)=\dot{m}_{13} h_{13}+\dot{m}_{7} h_{7}+\dot{m}_{34} h_{34}-\dot{m}_{25} h_{25} \\
\dot{Q}_{H P H, 2}=\dot{m}_{30}\left(h_{32}-h_{30}\right)=\dot{m}_{12} h_{12}+\dot{m}_{33} h_{33}-\dot{m}_{34} h_{34} \\
\dot{Q}_{H P H, 3}=\dot{m}_{30}\left(h_{32}-h_{31}\right)=\dot{m}_{10}\left(h_{10}-h_{33}\right)
\end{gathered}
$$

(iii) Energy balance in feedwater tank (FWT), moisture separator (MS), reheater (RH) and condenser;

$$
\dot{E}_{F W T}=\dot{m}_{28} h_{28}=\dot{m}_{14} h_{14}+\dot{m}_{27} h_{27}+\dot{m}_{35} h_{35}
$$




$$
\begin{gathered}
\dot{E}_{M S}=\dot{m}_{6} h_{6}=\dot{m}_{7} h_{7}+\dot{m}_{8} h_{8}+\dot{m}_{13} h_{13} \\
\dot{Q}_{R H}=\dot{m}_{9}\left(h_{9}-h_{10}\right)=\dot{m}_{8}\left(h_{11}-h_{8}\right) \\
\dot{Q}_{\text {Condenser }}=\dot{m}_{18}\left(h_{18}-h_{19}\right)=\dot{m}_{41}\left(h_{42}-h_{41}\right)
\end{gathered}
$$

(iv) Work consumed by each pump and the total pumping work required by the NPP;

$$
\begin{gathered}
\dot{W}_{\text {Pump }, 1}=\dot{m}_{20}\left(h_{20}-h_{19}\right) \\
\dot{W}_{\text {Pump }, 2}=\dot{m}_{43}\left(h_{36}-h_{43}\right) \\
\dot{W}_{\text {Pump }, 3}=\dot{m}_{29}\left(h_{29}-h_{28}\right) \\
\dot{W}_{\text {Pump }, 4}=\dot{m}_{3}\left(h_{3}-h_{2}\right) \\
\dot{W}_{\text {Total } \text { Pumps }}=\dot{W}_{\text {Pump }, 1}+\dot{W}_{\text {Pump }, 2}+\dot{W}_{\text {Pump }, 3}+\dot{W}_{\text {Pump }, 4}
\end{gathered}
$$

(v) Work performed by LPT and HPT plus the net work done by NPP and its thermal efficiency;

$$
\begin{gathered}
\dot{W}_{H P T}=\dot{m}_{5} h_{5}-\left(\dot{m}_{6} h_{6}+\dot{m}_{12} h_{12}\right) \\
\dot{W}_{L P T}=\dot{m}_{11} h_{11}-\left(\dot{m}_{14} h_{14}+\dot{m}_{15} h_{15}+\dot{m}_{16} h_{16}+\dot{m}_{17} h_{17}+\dot{m}_{18} h_{18}\right) \\
\dot{W}_{\text {Total,Turbines }}=\dot{W}_{H P T}+\dot{W}_{L P T} \\
\dot{W}_{\text {Net }, N P P}=\dot{W}_{H P T}+\dot{W}_{L P T}-\dot{W}_{\text {Total Pumps }} \\
\eta_{\text {Thermal }, N P P}=\frac{\dot{W}_{\text {net }, N P P}}{\dot{P}_{\text {Reactor }}}
\end{gathered}
$$

\subsection{Exergy model}

Based on Moran et al. [14], exergy accounts "the maximum theoretical work obtainable from an overall system consisting of a system and its surroundings as the system comes into equilibrium with the environment or passes to the dead state". So, exergy can be determined as a thermodynamic property. Then, the exergy flow in each point of Angra 2, already shown in Table 1, is calculated by Eq. (51). 


$$
\dot{E} x_{i}=\dot{m}_{i}\left[\left(h_{i}-h_{0}\right)-T_{0}\left(s_{i}-s_{0}\right)\right]
$$

Where, $\mathrm{h}_{0}$ and $\mathrm{s}_{0}$ are the thermodynamic properties enthalpy and entropy at dead state conditions ( $\mathrm{T}_{0}=25{ }^{\circ} \mathrm{C}$ and $\mathrm{P}_{0}=1 \mathrm{bar}$ ). According to the first law of thermodynamics, energy is always conserved in devices or processes. It can never be destroyed. In contrast, exergy never can be conserved during a process because some part of it will be destroyed by irreversibility like friction and heat transfer through a finite temperature difference [14].

Applying an exergy balance for a control volume during steady state conditions, Eq. (52), it is possible to determine the amount of exergy destroyed in every component of the NPP. This balance equation only considers the flows of exergy entering and leaving the system by both heat transfer and fluid flow.

$$
\sum\left(1-\frac{T_{0}}{T}\right) \dot{Q}+\sum \dot{E} x_{\text {in }}-\sum \dot{E} x_{\text {out }}-\dot{E} x_{\text {Destroyed }}=0
$$

In an alternative way of Eq. (52), when exergy by heat transfer can be neglected, the exergy destroyed in each individual device can be calculated based on the concepts of exergy as fuel and exergy as product as presented in Eq. (53) and used by many authors like Şöhret et al. [18] and Balli [19]. Exergy as fuel represents the exergy added to the system like when a fuel burns in a combustion chamber and adds heat to the working fluid that represents exergy as product. In an alternative way, exergy as fuel and product simply represent the difference between exergy flow in and exergy flow out as in Eq. (53).

$$
\dot{E} x_{\text {Destroyed }}=\dot{E} x_{\text {Fuel }}-\dot{E} x_{\text {Product }}=\sum \dot{E} x_{\text {in }}-\sum \dot{E} x_{\text {out }}
$$

Then, the exergy destroyed in every device of Angra 2 is calculated by Eq. (53) with the expressions of exergy as fuel and product defined in Table 3, considering all the exergy flows in each component.

Table 3: Exergy as fuel and product for each component of Angra 2. 


\begin{tabular}{|c|c|c|}
\hline Component & $\dot{E} x_{\text {Fuel }}$ & $\dot{E} x_{\text {Product }}$ \\
\hline Reactor & {$\left[1-\left(T_{o} / T_{\mathrm{Re} a c t o r}\right)\right] \dot{P}_{\mathrm{Re} a c t o r}$} & $\dot{E} x_{1}-\dot{E} x_{3}$ \\
\hline Steam Generator (SG) & $\dot{E} x_{1}-\dot{E} x_{2}$ & $\dot{E} x_{4}-\dot{E} x_{32}$ \\
\hline Moisture Separator (MS) & $\dot{E} x_{6}$ & $\dot{E} x_{7}-\dot{E} x_{8}-\dot{E} x_{13}$ \\
\hline Reheater $(\mathbf{R H})$ & $\dot{E} x_{9}-\dot{E} x_{10}$ & $\dot{E} x_{11}-\dot{E} x_{8}$ \\
\hline Condenser & $\dot{E} x_{18}-\dot{E} x_{19}$ & $\dot{E} x_{42}-\dot{E} x_{41}$ \\
\hline High Pressure Turbine (HPT) & $\dot{E} x_{5}-\dot{E} x_{12}-\dot{E} x_{6}$ & $\dot{W}_{H P T}$ \\
\hline Low Pressure Turbine (LPT) & $\dot{E} x_{11}-\dot{E} x_{14}-\dot{E} x_{15}-\dot{E} x_{16}-\dot{E} x_{17}-\dot{E} x_{18}$ & $\dot{W}_{L P T}$ \\
\hline Low Pressure Heater $1\left(\right.$ LPH $\left._{1}\right)$ & $\dot{E} x_{39}-\dot{E} x_{38}-\dot{E} x_{40}$ & $\dot{E} x_{22}-\dot{E} x_{21}$ \\
\hline Low Pressure Heater $2\left(\mathrm{LPH}_{2}\right)$ & $\dot{E} x_{37}-\dot{E} x_{39}$ & $\dot{E} x_{23}-\dot{E} x_{22}$ \\
\hline Low Pressure Heater $3\left(\mathrm{LPH}_{3}\right)$ & $\dot{E} x_{17}-\dot{E} x_{38}$ & $\dot{E} x_{24}-\dot{E} x_{23}$ \\
\hline Low Pressure Heater $4\left(\mathrm{LPH}_{4}\right)$ & $\dot{E} x_{16}-\dot{E} x_{37}$ & $\dot{E} x_{25}-\dot{E} x_{24}$ \\
\hline Low Pressure Heater $5\left(\right.$ LPH$\left._{5}\right)$ & $\dot{E} x_{15}-\dot{E} x_{43}$ & $\dot{E} x_{26}-\dot{E} x_{25}$ \\
\hline Feedwater Tank (FWT) & $\dot{E} x_{14}+\dot{E} x_{27}-\dot{E} x_{35}$ & $\dot{E} x_{28}$ \\
\hline High Pressure Heater $1\left(\mathrm{HPH}_{1}\right)$ & $\dot{E} x_{7}+\dot{E} x_{13}+\dot{E} x_{34}-\dot{E} x_{35}$ & $\dot{E} x_{30}-\dot{E} x_{29}$ \\
\hline High Pressure Heater $2\left(\mathrm{HPH}_{2}\right)$ & $\dot{E} x_{12}+\dot{E} x_{33}-\dot{E} x_{34}$ & $\dot{E} x_{31}-\dot{E} x_{30}$ \\
\hline High Pressure Heater $3\left(\mathrm{HPH}_{3}\right)$ & $\dot{E} x_{10}-\dot{E} x_{33}$ & $\dot{E} x_{32}-\dot{E} x_{31}$ \\
\hline Pump 1 & $\dot{W}_{\text {Pump }, 1}$ & $\dot{E} x_{20}-\dot{E} x_{19}$ \\
\hline Pump 2 & $\dot{W}_{\text {Pump }, 2}$ & $\dot{E} x_{36}-\dot{E} x_{43}$ \\
\hline Pump 3 & $\dot{W}_{\text {Pump }, 3}$ & $\dot{E} x_{29}-\dot{E} x_{28}$ \\
\hline Pump 4 & $\dot{W}_{\text {Pump }, 4}$ & $\dot{E} x_{3}-\dot{E} x_{2}$ \\
\hline
\end{tabular}

In the specific case of reactor, exergy as fuel is calculated by Eq. (54) based on reactor temperature $\left(\mathrm{T}_{\text {Reactor }}=800^{\circ} \mathrm{C}\right)$, environmental temperature $\left(\mathrm{T}_{0}\right)$ and also reactor thermal power $\left(\dot{\mathrm{P}}_{\text {Reactor }}\right)$.

$$
\dot{E} x_{\text {Fuel,Reactor }}=\left[1-\frac{T_{0}}{T_{\text {Reactor }}}\right] \dot{P}_{\text {Reactor }}
$$

Besides that, exergy destruction in reactor can be calculated according to Eq. (55) additionally to Eq. (53). This equation represents exergy destruction when the thermal power released by reactor core at $800{ }^{\circ} \mathrm{C}$ is transferred to the water coolant at a mean temperature ( $\left.\overline{\mathrm{T}}_{\text {Water }}\right)$ close to $308{ }^{\circ} \mathrm{C}$.

$$
\dot{E} x_{\text {Destroyed,Reactor }}=\left(\left[1-\frac{T_{0}}{T_{\text {Reactor }}}\right] \dot{P}_{\text {Reactor }}\right)-\left(\left[1-\frac{T_{0}}{\bar{T}_{\text {Water }}}\right] \dot{P}_{\text {Reactor }}\right)
$$


In this way, the total amount of exergy destroyed by the system and the exergy efficiency for each device can be respectively determined by Equations (56) and (57).

$$
\begin{gathered}
\dot{E} x_{\text {Destroyed }, N P P}=\sum \dot{E} x_{\text {Destroyed }} \\
\varepsilon=\frac{\dot{E} x_{\text {Product }}}{\dot{E} x_{\text {Fuel }}}=1-\frac{\dot{E} x_{\text {Destroyed }}}{\dot{E} x_{\text {Fuel }}}
\end{gathered}
$$

Additionally, the total amount of exergy in or supplied by the system and the total exergy out the NPP also its exergy efficiency are calculated according to the following equations:

$$
\begin{gathered}
\dot{E} x_{\text {Total,in }}=\dot{E} x_{\text {Fuel,Reactor }}+\dot{W}_{\text {Total,Pumps }} \\
\dot{E} x_{\text {Total,out }}=\dot{W}_{\text {Total,Turbines }} \\
\dot{E} x_{\text {Total,in }}=\dot{E} x_{\text {Total,out }}+\dot{E} x_{\text {Destroyed }, N P P} \\
\varepsilon_{N P P}=\frac{\dot{E} x_{\text {out }}}{\dot{E} x_{\text {Total, }, \text { in }}}=1-\frac{\dot{E} x_{\text {Destroyed }, N P P}}{\dot{E} x_{\text {Total, in }}}
\end{gathered}
$$

All equations presented in this section were implemented in EES software with the values of thermodynamic properties from Table 1 . The model described above neglects chemical exergy.

\section{RESULTS AND DISCUSSIONS}

In this section are presented and discussed the main results of the paper, including:

I. Heat exchanged and work related to each device of Angra 2 plus system thermal efficiency.

II. Exergy destroyed in all equipments of the nuclear power plant and its exergy efficiency.

\subsection{Energy Analysis}

The results presented in Table 4 are related to the energy model described in section 2.4 for Angra 2 NPP and its components. Remembering, the values of energy flow for each state, calculated by Eq. (26), were already shown in Table 1.

The highest values of heat exchanged considering low and high pressure heaters occur in $\mathrm{LPH}_{4}$ (217.2 MW), $\mathrm{LPH}_{5}(177.3 \mathrm{MW})$ and $\mathrm{HPH}_{2}$ (312.1 MW) and represent the energy added to the water, by recovering heat, to increase its temperature before it reaches steam generator, that increases 
system thermal efficiency. Additionally, reheater needs 198.9 MW to superheat steam, turning it from state 8 to 9 , before it drives low pressure turbine to produce electricity. Besides that, condenser releases $2,435 \mathrm{MW}$ to seawater, while the values of energy exchange in feedwater tank $(1,323$ $\mathrm{MW})$ and in moisture separator (4,489 MW) represent the balance between the total energy flows in and out in such devices.

LPT and HPT respectively produce 474.2 MW and 890 MW, representing a total work of 1,364.2 MW. Besides that, the net work done by the NPP corresponds to 1,317 MW because the system consumes 47.29 MW in 4 pumps. Additionally, reactor releases a thermal power of 3,771 MW. These values of net work and thermal power are close to the real values of Angra 2 provided by FSAR [13], and this validates the proposed model and its results. Finally, Angra 2 has thermal efficiency of $36 \%$; it is a common efficiency value for PWR plants or NPP systems like those ones available in the literature presented by Durmayaz and Yavuz [8] and Terzi et al. [12], what also validates the energy model.

Table 4: Energy values for each device and thermal efficiency of Angra 2.

\begin{tabular}{cc|cc|cc}
\hline Variable & Value [MW] & Variable & Value [MW] & Variable & Value[MW] \\
\hline$\dot{Q}_{L P H, 1}$ & 7.041 & $\dot{E}_{F W T}$ & 1,323 & $\dot{W}_{\text {Total,Turbines }}$ & $1,364.2$ \\
$\dot{Q}_{L P H, 2}$ & 24.52 & $\dot{E}_{M S}$ & 4,489 & $\dot{W}_{\text {Pump }, 1}$ & 2.23 \\
$\dot{Q}_{L P H, 3}$ & 54.55 & $\dot{Q}_{S G}$ & 3,791 & $\dot{W}_{\text {Pump }, 2}$ & 0.06 \\
$\dot{Q}_{L P H, 4}$ & 217.2 & $\dot{Q}_{\text {Condenser }}$ & 2,435 & $\dot{W}_{\text {Pump }, 3}$ & 21.46 \\
$\dot{Q}_{L P H, 5}$ & 177.3 & $\dot{Q}_{R H}$ & 198.9 & $\dot{W}_{\text {Pump }, 4}$ & 23.54 \\
$\dot{Q}_{H P H, 1}$ & 27.51 & $\dot{P}_{\text {Reactor }}$ & 3,771 & $\dot{W}_{\text {Total,Pumps }}$ & 47.29 \\
$\dot{Q}_{H P H, 2}$ & 312.1 & $\dot{W}_{H P T}$ & 474.2 & $\dot{W}_{\text {Net }, N P P}$ & 1,317 \\
$\dot{Q}_{H P H, 3}$ & 27.51 & $\dot{W}_{L P T}$ & 890 & $\eta_{\text {Thermal,NPP }}$ & $36.18 \%$ \\
\hline \multicolumn{2}{r}{}
\end{tabular}

\subsection{Exergy Analysis}

The values of exergy flow for every point of the NPP calculated by Eq. (51) were previously shown in Table 1. As can be seen in such table, the values of exergy flow are always smaller than the energy one to a well-defined thermodynamic state. It happens because exergy represents the amount of work that can be produced from an energy source based on dead state conditions, as represented in Eq. (51).

Additionally, Table 5 presents the values of exergy as fuel, exergy as product, exergy destroyed plus the exergy efficiency for Angra 2 and its components. According to the results, the main components responsible for exergy destruction (in MW or \%) are the reactor (894 MW or 63.88\%), low 
pressure turbine (124 MW or $8.83 \%$ ), condenser (120.29 MW or $8.58 \%$ ), steam generator (112 MW or $8.03 \%$ ), high pressure turbine (71.6 MW or $5.12 \%)$ and reheater $(22.91 \mathrm{MW}$ or $1.64 \%)$. These six components represent 96\% (134.5 MW) of all exergy destruction in Angra 2.

Table 5: Exergy values for Angra 2 and its components.

\begin{tabular}{cccccc}
\hline Component & $\begin{array}{c}\dot{E} x_{\text {Fuel }} \\
{[\mathbf{M W}]}\end{array}$ & $\begin{array}{c}\dot{E} x_{\text {Product }} \\
{[\mathbf{M W}]}\end{array}$ & $\begin{array}{c}\dot{E} x_{\text {Destroyed }} \\
{[\mathbf{M W}]}\end{array}$ & $\begin{array}{c}\dot{E} x_{\text {Destroyed }} \\
{[\%]}\end{array}$ & $\begin{array}{c}\varepsilon \\
{[\%]}\end{array}$ \\
\hline Reactor & 2,723 & 1,829 & 894 & 63.88 & 67.16 \\
Steam Generator & 1,849 & 1,737 & 112 & 8.03 & 93.92 \\
Moisture Separator & 1,332 & 1,328 & 4 & 0.28 & 99.75 \\
Reheater & 90.66 & 67.75 & 22.91 & 1.64 & 74.72 \\
Condenser & 121.1 & 0.81 & 120.29 & 8.58 & 0.67 \\
High Pressure Turbine & 545.8 & 474.2 & 71.6 & 5.12 & 86.88 \\
Low Pressure Turbine & 1,014 & 890 & 124 & 8.83 & 87.80 \\
Low Pressure Heater 1 & 0.38 & 0.22 & 0.16 & 0.01 & 56.26 \\
Low Pressure Heater 2 & 3.25 & 1.13 & 2.12 & 0.15 & 34.80 \\
Low Pressure Heater 3 & 4.95 & 3.76 & 1.19 & 0.08 & 76.07 \\
Low Pressure Heater 4 & 42.2 & 29.51 & 12.69 & 0.91 & 69.94 \\
Low Pressure Heater 5 & 44.8 & 38.57 & 6.23 & 0.44 & 86.11 \\
Feed Water Tank & 190.7 & 185.7 & 5 & 0.36 & 97.35 \\
High Pressure Heater 1 & 89.17 & 84.15 & 5.02 & 0.36 & 94.37 \\
High Pressure Heater 2 & 124.5 & 114.8 & 9.7 & 0.69 & 92.21 \\
High Pressure Heater 3 & 12.14 & 9.15 & 2.99 & 0.21 & 75.41 \\
Pump 1 & 2.23 & 1.19 & 1.04 & 0.023 & 85.62 \\
Pump 2 & 0.05 & 0.04 & 0.01 & 0.0007 & 80.64 \\
Pump 3 & 21.46 & 18.7 & 2.76 & 0.19 & 87.14 \\
Pump 4 & 23.54 & 20.16 & 3.38 & 0.24 & 85.64 \\
\hline Angra 2 NPP & $\dot{E} x_{\text {Total,in }}$ & $\dot{E} x_{\text {Total,out }}$ & $\dot{E} x_{\text {Destroyed,NPP }}$ & $\boldsymbol{E}_{N P P}$ & \\
\hline
\end{tabular}

The reactor core is the most inefficient device in the NPP, as previously discussed by Durmayaz and Yavuz [8] and Terzi et al. [12]. It has exergy efficiency of $67.16 \%$ and destroys $894 \mathrm{MW}$, the equivalent to $63.88 \%$ of all exergy destruction in Angra 2. It happens because the thermal power released by reactor core at $800{ }^{\circ} \mathrm{C}$ is added to the water coolant at around $308^{\circ} \mathrm{C}$ by heat transfer. In this way, according to equations (54) and (55), how higher is the difference temperature between the reactor core and water coolant, the higher will be exergy destruction, reducing system overall performance.

Low and high pressure turbines destroy 124 MW and 71.6 MW respectively, equivalent to $8.83 \%$ and $5.12 \%$ of all exergy destroyed in Angra 2, during electricity production due to alterations in steam thermodynamic conditions, like enthalpy and entropy, as it pass through such devices. Both LPT and HPT have high exergy efficiency close to $87 \%$. On the other hand, steam generator and reheater destroy respectively $112 \mathrm{MW}$ and $22.91 \mathrm{MW}$, equivalent to $8.03 \%$ and $1.64 \%$ of all exergy 
destroyed in the NPP, during heat transfer processes to produce and superheat steam. Condenser has exergy efficiency of $0.67 \%$ and destroys $120.29 \mathrm{MW}$ or $8.58 \%$ of the total exergy destruction. LPHs, HPHs and pumps, represent $4 \%$ of the total exergy destroyed in the plant.

Finally, Angra 2 NPP has exergy efficiency of $49.24 \%$, based on a total exergy in of 2770 MW supplied by reactor and pumps with a total amount of exergy destruction of 1,400 MW in its components plus an exergy out of 1,364 in the form of net work performed by HPT and LPT. There is a small difference of $6 \mathrm{MW}$ among the total net flow of exergy in and out that represents the errors related to the output values of properties like entropy and enthalpy provided by EES software. Therefore, the value of exergy efficiency for Angra 2 and its components are close to some values available in the literature for nuclear power plants, like those presented by Durmayaz and Yavuz [8] and Terzi et al. [12], validating the proposed model and its results.

\section{CONCLUSIONS AND FUTURE IDEAS}

The aim of the paper was to evaluate Angra 2 NPP and its components based on energy and exergy analyses in order to quantify system thermodynamic performance. It was also possible to determine the most inefficient devices in the plant. According to the results, Angra 2 has energy efficiency of $36.18 \%$ and exergy efficiency of $49.24 \%$. Reactor core is the most inefficient device in the NPP; it has exergy efficiency of $67.16 \%$ and is responsible for $63.88 \%$ of all exergy destroyed in Angra 2. So, the aim of the paper was achieved.

Additionally, in next step it will be performed an advanced exergy analysis to assess Angra 2 NPP and its components in order to better understand the entire system and identify its true potential for improvements. Advanced exergy is a relatively new methodology and complements the traditional exergy approach. It has been addressed by many authors like Şöhret et al. [18] and Balli [19] to evaluate many different thermal systems or power plants.

\section{ACKNOWLEDGMENTS}

The authors are grateful to the Coordenação de Aperfeiçoamento de Pessoal de Nivel Superior (CAPES), the Fundação de Amparo à Pesquisa do Estado de Minas Gerais (FAPEMIG), and the Conselho Nacional de Desenvolvimento Científico e Tecnológico (CNPq) for the support.

\section{REFERENCES}


1. OZCAN, H.; DINCER, I. Thermodynamic modeling of a nuclear energy based integrated system for hydrogen production and liquefaction. Comput. Chem. Eng., v. 90, p. 234-246, 2016.

2. KOMIYAMA, R.; FUJII, Y. Long-term scenario analysis of nuclear energy and variable renewables in Japan's power generation mix considering flexible power resources. Energy Policy, v. 83, p. 169-184, 2015.

3. KHALID, F.; DINCER, I.; ROSEN, M. A. Comparative assessment of CANDU 6 and Sodium-cooled Fast Reactors for nuclear desalination. Desalination, v. 379, p. 182-192, 2016.

4. HUHTALA, A.; REMES, P. Quantifying the social costs of nuclear energy: Perceived risk of accident at nuclear power plants. Energy Policy, v. 105, p. 320-331, 2017.

5. Eletrobras Eletronuclear: Panorama da energia nuclear no mundo - edição de 2016, Available

at:<http://www.eletronuclear.gov.br/LinkClick.aspx?fileticket=SG_9CnL80wM\%3d\&tabid $=406>$. Last accessed: 27 Nov. 2017.

6. VERKHIVKER, G. P.; KOSOY, B. V. On the exergy analysis of power plants. Energy Convers. Manag., v. 42, n. 18, p. 2053-2059, 2001.

7. MANESH, M. H. K.; AMIDPOUR, M. Multi-objective thermoeconomic optimization of coupling MSF desalination with PWR nuclear power plant through evolutionary algorithms. Desalination, v. 249, n. 3, p. 1332-1344, 2009.

8. DURMAYAZ, A.; YAVUZ, H. Exergy analysis of a pressurized-water reactor nuclearpower plant. Appl. Energy, v. 69, n. 1, p. 39-57, 2001.

9. ZARE, V.; MAHMOUDI, S. M. S.; YARI, M. Ammonia-water cogeneration cycle for utilizing waste heat from the GT-MHR plant. Appl. Therm. Eng., v. 48, p. 176-185, 2012.

10. YARI, M; MAHMOUDI, S. M. S. Utilization of waste heat from GT-MHR for power generation in organic Rankine cycles. Appl. Therm. Eng., v. 30, n. 4, p. 366-375, 2010.

11. AL-ZAREER, M.; DINCER, I.; ROSEN, M. A. Development and assessment of a novel integrated nuclear plant for electricity and hydrogen production. Energy Convers. Manag., v. 134, p. 221-234, 2017.

12. TERZI, R.; TÜKENMEZ, İ.; KURT, E. Energy and exergy analyses of a VVER type nuclear power plant. Int J Hydrogen Energy, v. 41, n. 29, p. 12465-12476, 2016.

13. Final Safety Analysis Report (FSAR), (2013).

14. MORAN M. J.; SHAPIRO, H. N.; BOETTNER, D. D.; BAILEY, M. B. Fundamentals of Engineering Thermodynamics. John Wiley \& Sons. 2011. 
15. KLEIN, S.; NELLIS, G. Thermodynamics. New York: Cambridge. 2012.

16. BORGNAKKE, C.; SONNTAG, R. E. Fundamentals of Thermodynamics. Wiley Global Education. 2016.

17. Eletrobras Eletronuclear: Angra 2. Available at: <http://www.eletronuclear.gov.br/aempresa/centralnuclear/angra2.aspx>. Last accessed: 27 Nov. 2017.

18. ŞÖHRET, Y. et al. Advanced exergy analysis of an aircraft gas turbine engine: Splitting exergy destructions into parts. Energy, v. 90, p. 1219-1228, 2015.

19. BALLI, O. Advanced exergy analyses of an aircraft turboprop engine (TPE). Energy, v. 124, p. 599-612, 2017. 